Чеботарева Ю.В.

\title{
Трактовка жанра скрипичного концерта в творчестве Генрика Венявского
}

Аннотация: Актуальность данного исследования обусловливается популяризацией романтического направления в современной музыке, ориентацией на романтические стилевые тенденции среди композиторов и исполнителей. В этой связи обращение к творчеству ярчайшего представителя романтического течения в музыке польского скрипача и композитора Генрика Венявского представляет несомненную важность. Яркое, фееричное, в то же время философски-глубокое творчество Венявского открыло путь к новым достижениям, новым вершинам, иным путям развития скрипичного искусства, помогая развивать современное скрипичное исполнительство. Предметом исследования являются два произведения Генрика Венявского в жанре скрипичного концерта, где наиболее ярко проявляется творческий стиль композитора и прослеживается его развитие. Автором предпринята попытка обратить внимание современных педагогов и исполнителей к авторскому замыслу и глубокому концептуальному решению композитора, в частности, во Втором концерте. Основой исследования является комплексный теоретико-исполнительский подход, который обусловливает использование метода сравнительного анализа скрипичнъх концертов Генрика Венявского с точки зрения рассматриваемых в работе компонентов. Научная новизна данного исследования определяется параметрами сравнительного анализа двух скрипичных концертов Генрика Венявского с позиции рассмотрения содержательно-музыкальных и стилистических особенностей, присущих данным произведениям. В результате исследования были сделаны выводы, свидетельствующие об эволюции композиторского мышления польского музыканта на уровне стиля, особенностей применения выразительных средств, принципов симфонизации. Полученные результаты могут являться важным источником для дальнейшего изучения творчества польского скрипача и композитора Генрика Венявского, а также способствовать изучению путей развития в области европейского романтического искусства.

Ключевые слова: Монотематизм, моноинтонационность, приемы драматургического развития, романтический лирический жанр, виртуозно-романтический жанр, скрипичный концерт, Генрик Венявский, композиционная логика, инструментальная орнаментальность, концептуальный тип мышления.

Review: The importance of the present research is caused by the growing popularity of the romantic music genre and orientation at romantic styles and trends demonstrated by contemporary composers and players. In this regard, it is very important to appeal to the creative life and work of the most brilliant representatives of the romantic movement in music, Polish violinist and composer Henryk Wieniawski. Remarkable and spectaculous and at the same time philosophical compositions of Wieniawsky opened the door to new discoveries, heights and directions for the development of the violin art, thus helping to develop the genre of violin concert. The subject of the research is the two compositions of Henryk Wieniawski in the genre of violin concert as the brightest example of his creative style. The author of the article makes an attempt to draw attention of modern music teachers and players to the composer's intention and profound conceptual solutions, in particular, in his Second concert. The research is based on the integrated theoretical and practical approach and the method of comparative analysis of these two Henryk Wieniawski's violin concerts in terms of the research subject. The scientific novelty of the research is caused by the fact that the author describes parameters for the comparative analysis of the two violin concerts composed by Henryk Wieniawski from the point of view of their concent and style. As a result of the research, the author makes conclusions about the development of the Polish composer's style and way of thinking, peculiarities of his expressive means and symphonization principles. The results of the research can be important for further researches of the creative life and work of the Polish composer and violonist Henryk Wieniawski as well as encourage further studies of European romantic art.

Keywords: Virtuosic romantic genre, romantic lyrical genre, narrative methods, monointonationalism, monothematism, composition logic, instrumental ornamentality, conceptual way of thinking, violin concert, Henryk Wieniawski. 
$\Gamma$ енрик Венявский вошел в историю скрипичного искусства как один из крупнейших музыкантов, самобытный талант которого в равной степени отразился в его исполнительском искусстве и композиторском мастерстве. Его творчество ознаменовало собой расцвет польской скрипичной культуры. Облик Генрика Венявского как композитора формировался под влиянием польского музыкального фольклора, искусства Ф. Шопена, С. Монюшко, К. Липиньского. Благодаря удивительному мелодическому дарованию, именно славянское песенное начало и лирическая сторона получили значительное развитие в творчестве Генрика Венявского. В романтических образах своих сочинений он стремился к максимальному выражению реальной жизни и мира человеческих переживаний. В то же время своим творчеством Венявский продолжил прогрессивные традиции скрипичного виртуозного искусства Н. Паганини, Г. Эрнста, А. Вьётана, создавая блестящие эффектные произведения. Благодаря мастерскому владению всеми видами скрипичной техники и умелому применению их в качестве логического средства музыкальной выразительности и развития музыкального образа, Венявскому удалось максимально раскрыть природу инструмента и его темброво-выразительные возможности.

Композиторское дарование Генрика Венявского высоко ценили ведущие европейские деятели искусства и культуры: А. Рубинштейн, А. Серов, П. Чайковский, Ц. Кюи, А. Бородин, Ф. Лист, Г. Берлиоз, Л. Ауэр, И. Тургенев. Венявский был ярким, талантливым представителем того романтического искусства, где виртуозная сторона никогда не рассматривалась исключительно как способ проявления технических возможностей исполнителя, а воспринималась как важный элемент выразительности, способствуя воплощению художественных задач. Так, Вторым скрипичным концертом, в котором ему удалось соединить казалось бы, невозможное: глубокую музыкальную поэтику, нашедшую удивительно тонкое воплощение в инструментальной стихии с высочайшей виртуозностью, полной свободы и праздника инструментальности, Венявский подтвердил и воплотил замечание Листа относительно «доблести», как проникновения в самую суть инструмента. Неслучайно, именно эта сторона творчества польского музыканта получила высокую оценку и поддержку
А.Г. Рубинштейна, стоявшего за дирижерским пультом в день премьеры Второго скрипичного концерта 27 ноября 1862 года. Именно ему принадлежат знаменитые слова об отношении виртуозности и музыкальности: «Восстают против тех, которые употребляют виртуозность как цель, а не как средство. Я отчасти против такого идеального взгляда... Очень хороших фортепианистов нынче много, но виртуозов на этом инструменте в смысле двигающего вперед, я, как последнего, могу назвать только Таузига; по части скрипки Венявского, по части виолончели Давыдова и по части пения Виардо-Гарсиа» [6, с. 113-114]. По мнению М.Л. Зайцевой, «подлинная виртуозность, будучи тесно связана с эмоционально-смысловой целью, поставленной перед собой исполнителем, является прямым следствием образно-звуковых представлений музыканта. Она обусловлена художественной активностью, творческой смелостью, способностью к яркому выражению эмоционального накала» [5, с. 56].

Скрипичные концерты Генрика Венявского являются неотъемлемой частью скрипичного репертуара. Они были популярны при жизни композитора и остаются актуальными в настоящее время. О сохраняющемся до сих пор значении скрипичных концертов Генрика Венявского говорит не только включение их в конкурсные и педагогические программы, но и внимание, уделяемое им на страницах диссертационных исследований, учебных и методических пособий, принадлежащих крупнейшим педагогам и методистам. Так, в первом томе «Искусства скрипичной игры» К. Флеша (Flesch Carl. Die Kunst des Violinspiels. Bd. I-II. Berlin, 1923, 1928. Первый том издан в русском переводе в редакции и с комментариями К.А. Фортунатова. М., 1964) имеются неоднократные ссылки на концерты Венявского. $\mathrm{C}$ позиции исполнительских рекомендаций они рассматриваются в книге Л.С. Ауэра в книге «Моя школа игры на скрипке. Интерпретация произведений скрипичной классики» (M., 1965). Примеры из концертов содержатся в методических трудах К.Г. Мостраса «Очерки по методике обучения игре на скрипке. Вопросы техники левой руки скрипача» (М., 1960). И.А. Лесмана «Очерки по методике обучения игре на скрипке» (М., 1968); И.М. Ямпольского «Основы скрипичной аппликатуры» (4-е изд. М., 1974). В качестве основного труда, где рассматривается творчество Генрика Венявского и, в частности, его композитор- 
ские стилевые особенности, следует назвать диссертационную работу доктора искусствоведения В.Ю. Григорьева «История польского скрипичного искусства XIX века» (М., 1981). Среди последних исследований, в которых освещается композиторское наследие Генрика Венявского в жанре скрипичного концерта, следует обозначить диссертацию А.В. Анисимова «Взаимодействие солиста и оркестра в западноевропейском скрипичном концерте XVII-XIX веков» (Магнитогорск, 2011).

Жанр скрипичного концерта в творчестве Генрика Венявского представляет собой своеобразную творческую «лабораторию», в которой проявились различные грани его мастерства, нашли преломление те или иные влияния различных композиторских стилей. Резкая смена стилистики раннего и более зрелого скрипичных концертов позволяет выявить особенности творческого метода разных этапов жизни композитора, определить специфику трактовки композитором данного жанра. Проследим эволюцию композиторского стиля Г. Венявского на примере анализа двух его концертов, созданных на протяжении одного десятилетия, но обнаруживающих резкий перелом в представлениях автора о музыкальной драматургии и композиции: Первого концерта для скрипки с оркестром fis-moll op. 14 (1853 г.) и Второго концерта для скрипки с оркестром d-moll op. 22 (1862 г.).

Первый скрипичный концерт стал итогом поисков Венявского в области масштабной романтической виртуозности. Доминирует здесь исполнительский стиль с характерным патетическим настроем, определяющий характер образности, форму, специфичность выразительных средств с применением сложных технических комбинаций. По словам Л.С. Ауэра, «героическая тема первой части говорит о том, что это произведение было написано художником, стремившимся сказать в концертном жанре новое слово, раскрыть свои блестящие, можно сказать, феноменальные виртуозные возможности» [2, с. 193].

В концерте можно заметить черты разностильности, связанные, вероятно, с тем, что его части создавались в разных местах. Сочинение концерта относят к 1852 году, когда Венявский гастролировал по городам России, однако завершен концерт был в Веймаре в 1853 году. В концерте прослеживается сходство интонаций и структуры многих тем концерта, что придает ему внутреннюю цельность. Анализ приемов драматургического развития, использованных в Первом скрипичном концерте, позволяет выявить общность творческих установок Г. Венявского и Ф. Листа, с которым молодой композитор познакомился в Веймаре в 1853 году, и даже брал у него уроки. Излюбленный прием «листовского» монотематизма отразился в моноинтонационных находках Венявского (вторая тема первой части, вторая тема финала, главная тема второй части). Не обошлось здесь и без влияния тенденций ведущих скрипачей-композиторов. Традиции Липиньского проявляются в «народных» элементах; в удивительно продуманном диалоге сольной и оркестровой партии слышен Вьётан; в ярких колористических средствах и виртуозной фееричности заметно влияние Паганини.

Несмотря на классическую трехчастность, Первый концерт Венявского заметно отличается от всех предыдущих произведений в этом жанре резким контрастным характером построения. Различные по своему складу темы постоянно чередуются друг с другом, что позволяет провести параллель с возрождающимся в эстетике романтизма фольклорным жанром рапсодии.

В концерте fis-moll Венявский удачно coчетает виртуозность сольной партии с оркестровой симфоничностью и разработкой тематического материала. Прослеживается драматический конфликт солиста и оркестра на уровне чередования эпизодов и внутри тематического материала [1, с. 121]. Среди новаций оркестрового письма выделяется красочность оркестровой партии и постоянная трансформация оркестровой фактуры на уровне сочетания аккордового и фигурационного типа изложения.

Первый скрипичный концерт Генрика Beнявского, характеризующий блестящее профессиональное исполнительское искусство, завершает линию «большого» виртуозно-романтического концерта, идущую от Н. Паганини, Г. Эрнста и А. Вьётана. Музыкальный критик газеты «Signale für die musikalische Welt» писал: «Если подлинный композиторский талант выявляет оригинальный замысел в целом, отдельные изумляющие мысли, блестки инструментовки, пикантные контрасты, огненное глубокое чувство, связанное с чувством формы, то все это г-н Г. Венявский получил от природы. Пусть этот талант еще не полностью выявился. Все это придет со временем при такой высокой одаренности» $[7$, с. 73]. Так, индивидуальный стиль Веняв- 
ского получил наиболее полное выражение во Втором скрипичном концерте.

Углубление художественного мировоззрения Генрика Венявского, произошедшее в середине 50-х годов, заметно отразилось в игре польского скрипача и в его сочинениях, где большое развитие приобрела выразительная сторона, мелодичность, яркость музыкальных образов. Значительных изменений творчество Г. Венявского коснулось в годы пребывания в России. Его устремления оказались весьма близкими нарождающимся тенденциям русской культуры. Здесь он создает наиболее значительные произведения - Фантазию на темы оперы «Фауст» Ш. Гуно (op. 20), Полонез A-dur (op. 21), Концерт для скрипки № 2 d-moll (op.22).

По мнению В.Ю. Григорьева «Век виртуозности утрачивал свое дыхание, требовалось соответствовать новой складывающейся атмосфере искусства, все более склоняющегося к концептуальному мышлению. В этой ситуации и виртуозно-романтическое полотно изменяло свою внутреннюю сущность» [4, с. 276]. В этой атмосфере и возник Второй скрипичный концерт (посвящен выдающемуся испанскому скрипачу Пабло де Сарасате), в котором творческая фигура Генрика Венявского предстала в феноменальном проявлении композиторского единства лирика, драматурга и симфониста. Глубокая поэтичность и одухотворенность музыки, органичность и цельность формы, богатство фактуры, красота мелодии делают его одним из любимых произведений скрипичной литературы. Стремление к внешнему, свойственному романтической эпохе виртуозному пафосу, отходит на второй план. В музыке концерта можно проследить благотворное влияние произведений Ф. Шопена и П. Чайковского.

Самобытной стороной концерта является его декоративная орнаментальность, органически сочетающаяся с напевной выразительностью каждой фразы. Эта орнаментальность определяется, прежде всего, знанием композитора особенностей скрипичного исполнительского искусства, пониманием природы звука, технических и колористических возможностей инструмента. В данном случае можно провести аналогию с А. Вьётаном, мастерски применяющим выразительные возможности скрипки, используя лишь те виртуозные эффекты, которые логически определялись художественным замыслом. Второй концерт Венявского является произведением, в котором композитор демонстрирует совершенство композиционной логики, сложность фактурного решения музыкальной ткани, насыщенной полифоническими подголосками. Данное сочинение отличает сложное взаимодействие оркестровой и сольной партии, выражающееся на мелодическом, полифоническом и симфоническом уровнях. Венявский расширяет мелодические возможности инструментов оркестра и темброво-динамические соотношения с солирующей скрипкой. Основной функцией оркестра становится раскрытие и дополнение основных образов сольного инструмента. Средства музыкальной выразительности, применяемой им в данном произведении, позволяют добиться особой динамичности и драматизма в соединении мелодических линий, фраз, интонаций, наполняют концерт особой экспрессией.

Впервые в истории скрипичной литературы композитор проводит через все части концерта одну тему (главная тема первой части), которая получает различное освещение в каждой части концертного цикла. Это вызвано стремлением Венявского воплотить в концерте определенную программу, о чем свидетельствует не только высказывания самого композитора, но и конкретность, выразительность, рельефность музыкальных образов [3, с. 96]. Показательным в этом смысле представляется высказывание В. Ю. Григорьева, по мнению которого «вторая часть по драматургии не является самостоятельной, ее можно рассматривать как своеобразные лирические вариации, в которых разрабатываются интонации лирической темы первой части» [4, с. 290-291]. Возможно, подобная точка зрения связана также с тем, что вторая часть как-бы музыкально-логически «вытекает» из первой. Финальное оркестровое tutti непосредственно переходит в начало второй части. Однако, на наш взгляд, несмотря на интонационную схожесть тем с первой частью, вторая часть Концерта d-moll - это важный, самостоятельный и динамичный раздел концертного цикла. По словам Л.С. Ауэра «Это песня, которая должна быть «спета» так, чтобы слушатель забыл о том, как она исполняется на инструменте» [2, с. 197]. Неслучаен выбор названия части - «Romance», к жанру которого Венявский всегда тяготел. Исполняя романсы А. Вьётана и Л. в. Бетховена, он погружался в атмосферу романтической мечтательности, которая была ему чрезвычайно близка. Так, мечтательно-элегический образ был воплощен Ве- 
нявским во второй части d-moll'ного цикла, ставшего своеобразным лирическим центром произведения.

Обобщая вышесказанное, отметим, что в результате сравнительного анализа двух скрипичных концертов Генрика Венявского были сделаны важные выводы, свидетельствующие об эволюции композиторского мышления польского музыканта на уровне стиля, особенностей применения выразительных средств, принципов симфонизации.

Скрипичный концерт № 1 fis-moll представляет собой образец виртуозно-романтического жанра. В данном произведении проявилась склонность композитора к преувеличенной патетике и обильному применению сложных технических комбинаций. Заметно ощущается развитие исполнительских принципов, характерных для творчества Н. Паганини, Г. Эрнста, А. Вьётана.

Скрипичный концерт №. 2 d-moll характеризует глубокое лирическое начало с тонкой внутренней линией психологизма, виртуозные элементы отходят на второй план, выполняя исключительно выразительноколористическую функцию (отказ от виртуозной каденции); в то же время заметно усиливается драматическое напряжение за счет использования монотематического принципа изложения и развития музыкального материала. В стилевом отношении можно проследить сходство Второго концерта Веняв- ского со скрипичными концертами Ф. Мендельсона и А. Вьётана.

Полученные результаты могут являться важным источником для дальнейшего изучения творчества польского скрипача и композитора Генрика Венявского, а также способствовать изучению путей развития в области европейского романтического искусства.

Творчество польского скрипача и композитора Генрика Венявского ознаменовало собой расцвет мирового скрипичного искусства. Как композитор, Венявский сумел отразить в своих произведениях основные тенденции эпохи, сочетая эффектность и блеск виртуозности со значительным художественным содержанием, передающим сложную гамму человеческих чувств. Деятельность Венявского подводит своеобразный итог предыдущему этапу развития скрипичного искусства в сочетании с авторскими традициями, открывающими новые пути развития. В его творчестве нашли максимальное выражение основные тенденции эпохи: близость исполнительского и композиторского творчества, развитие выразительных свойств и средств инструмента. Наследие польского композитора следует рассматривать как непосредственное продолжение, составную часть исполнительской деятельности артиста, неразрывно связанную с обликом концертного солиста, отражающую его исполнительский стиль, особенности скрипичной техники, круг излюбленных образов.

\section{Библиография:}

1. Анисимов А.В. Взаимодействие солиста и оркестра в западноевропейском скрипичном концерте XVIIXIX веков Текст: дис. ... к-та искусствоведения. Магнитогорск, 2011. 248 с.

2. Ауэр Л. Моя школа игры на скрипке. Интерпретация произведений скрипичной классики. М.: Музыка, 1965. $274 \mathrm{c}$.

3. Григорьев В.Ю. Генрик Венявский. М.: Музыка, 1966. 118 с.

4. Григорьев В.Ю. История польского скрипичного искусства XIX века Текст: дис. ... д-ра искусствоведения. М., 1981. 381 c.

5. Зайцева М.Л. Виртуозность и расширение границ восприятия музыкального исполнительского искусства / М.Л. Зайцева // Материалы XII международной научно-практической конференции «Ключевые аспекты научной деятельности - 2016» (7-15 января 2016 г., Польша, г. Перемышль). Т. 5. Музыка и жизнь. Перемышль: Nauka i studia, 2016. С. 55-57.

6. Рубинштейн А.Г. Музыка и ее представители. М.: Паровая скоропечатня нот П. Юргенсона, 1891.185 с.

7. «Signale fur die musikalische Welt», Leipzig, 1853 / Григорьев В.Ю. Генрик Венявский. М.: Музыка, 1966.118 с.

\section{References (transliterated):}

1. Anisimov A.V. Vzaimodeistvie solista i orkestra v zapadnoevropeiskom skripichnom kontserte XVII-XIX vekov Tekst: dis. ... k-ta iskusstvovedeniya. Magnitogorsk, 2011. 248 s. 
2. Auer L. Moya shkola igry na skripke. Interpretatsiya proizvedenii skripichnoi klassiki. M.: Muzyka, 1965. 274 s.

3. Grigor'ev V.Yu. Genrik Venyavskii. M.: Muzyka, 1966. 118 s.

4. Grigor'ev V.Yu. Istoriya pol'skogo skripichnogo iskusstva XIX veka Tekst: dis. ... d-ra iskusstvovedeniya. M., $1981.381 \mathrm{~s}$.

5. Zaitseva M.L. Virtuoznost' i rasshirenie granits vospriyatiya muzykal'nogo ispolnitel'skogo iskusstva / M.L. Zaitseva // Materialy XII mezhdunarodnoi nauchno-prakticheskoi konferentsii «Klyuchevye aspekty nauchnoi deyatel'nosti - 2016» (7-15 yanvarya 2016 g., Pol'sha, g. Peremyshl'). T. 5. Muzyka i zhizn'. Peremyshl': Nauka i studia, 2016. S. 55-57.

6. Rubinshtein A.G. Muzyka i ee predstaviteli. M.: Parovaya skoropechatnya not P. Yurgensona, 1891. $185 \mathrm{~s}$.

7. «Signale fur die musikalische Welt», Leipzig, 1853 / Grigor'ev V.Yu. Genrik Venyavskii. M.: Muzyka, $1966.118 \mathrm{~s}$. 